\title{
Initiation, continuation of use and cessation of alternative tobacco products among young adults: A qualitative study
}

\author{
Milkie Vu', Betelihem Getachew', Jackelyn B. Payne', Thomas R. Kirchner', Carla J. Berg'
}

\begin{abstract}
INTRODUCTION Diverse non-cigarette alternative tobacco products are increasingly popular in the United States. This study investigates the reasons why young adults initiate and continue the use of these products, as well as potential motivations and approaches for quitting. Products assessed include cigarettes, little cigars/cigarillos (LCCs), smokeless tobacco, e-cigarettes, and hookahs. METHOdS We conducted 60 telephone interviews, of 30-minute duration, with tobacco users enrolled in colleges in Georgia. Qualitative analysis was used to identify themes emerging from the data.

RESULTS Reasons for initiation, continued use, and (potential) cessation showed similarities and differences across products. Most commonly cited reasons for initiation included: peer influence (all products), flavors/tastes (all products except cigarettes), and easy environmental access and/or low costs (LCCs, smokeless tobacco, and e-cigarettes). Participants discussed several influences on continued use, such as peer influence (cigarettes, LCCs, and hookahs), stress management (all products except hookahs), and use with other substances (cigarettes, LCGs, and hookahs). Primary motivations for cessation mentioned by participants were family responsibilities (cigarettes, e-cigarettes, and hookahs) and health concerns (all products except e-cigarettes). Frequently used cessation strategies included avoidance of other tobacco users (cigarettes, LCCs, and hookahs) and a reduction of nicotine intake (cigarettes and e-cigarettes).

CONCLUSIONS Our findings suggest that researchers should consider the differences in reasons for use and discontinued use of tobacco products in order to develop targeted messaging strategies, particularly noting the differential impact of interpersonal influences and health concerns. We also point to a need for regulatory action that limits diversification and accessibility of different products.
\end{abstract}

\section{AFFILIATION \\ 1 Department of Behavioral Sciences and Health Education, Emory University, Atlanta, United States \\ 2 College of Global Public Health, New York University, New York City, United States \\ CORRESPONDENCE TO \\ Carla J. Berg. Emory University, 1518 Clifton Rd NE, 30322 Atlanta, United States. E-mail: cjberg@emory.edu \\ KEYWORDS \\ qualitative research, young adults, alternative tobacco products, tobacco use, college students}

Received: 1 October 2017 Revised: 19 November 2017 Accepted: 28 January 2018

\section{INTRODUCTION}

The rates of cigarette smoking in the United States have declined over the past few decades due to increasing knowledge of health consequences, higher regulations and prices, and changing norms ${ }^{1}$. However, the recent emergence and rising popularity of diverse non-cigarette alternative tobacco products (ATPs) represent new challenges for tobacco control efforts. Commonly used non-cigarette tobacco products include little cigars/cigarillos (LCCs), smokeless tobacco, e-cigarettes, and hookahs. ATPs are becoming more popular in the United State ${ }^{1-3}$. Recent research conducted in 2010 found that $13.6 \%$ of adults and $25.1 \%$ of daily smokers in the United States had tried one or more of non-cigarette tobacco products $^{4}$. In addition, a study found that $6.6 \%$ of adults in the United States are using these products exclusively and $10.6 \%$ are using dual cigarette and non-cigarette products 5 .

The use of ATPs among young adults is particularly 
concerning, given that this group is more aware of ATPs and more likely to try ATPs. Compared to other age groups, young adults between the ages of 18 and 24 years are more likely to have heard of $\mathrm{ATPs}^{6}$; a study in 2010 found that $18 \%$ of young adult respondents reported having tried at least one such product ${ }^{4}$. Evidence also shows that tobacco companies are targeting youth audience for the market of ATPs ${ }^{7-10}$, and that young adults are exposed to a fair amount of advertising for tobacco products on a weekly basis ${ }^{11}$.

The transition to college is a critical period for young adults, when many engage in compromising health behaviors including tobacco use ${ }^{2}$. A body of research has emerged in recent years on young adult college students' use of ATPs. Studies have examined predictors of use, trends of dual or poly-tobacco use, as well as perceptions of harms of different products in this population ${ }^{2,12-19}$. For example, certain sociodemographic (i.e. being male ${ }^{13,14,16}$ ) and psychosocial factors (i.e. having favorable attitudes towards smoking ${ }^{14}$, or perceiving peer use of tobacco products ${ }^{15}$ ) have been linked to use of ATPs. Research also shows that poly-tobacco use is more prevalent than single-product use among college students ${ }^{16}$. In addition, while young adult college students have little understanding of possible health risks associated with ATPs (e.g. cancer risks associated with chewing tobacco $)^{7,15}$, they also have indicated higher acceptance of these products compared to traditional cigarettes ${ }^{18}$.

Despite these findings, more research is needed regarding the reasons why young adults initiate and continue the use of a range of these tobacco products. Moreover, we must examine the reasons why they may be motivated to quit and strategies or approaches for cessation, as these topics have yet to receive much attention. Information on reasons for the initiation, continuation, and cessation of tobacco products is needed given the changing landscape of tobacco-use patterns, the diversification of ATPs, and the range of use patterns across products ${ }^{20}$. Research should explore not only the reasons for use and discontinuation of ATPs as a whole, but also whether these reasons might hold or differ across the range of diverse tobacco products, since preliminary evidence has indicated that motives for use may differ across products for single tobacco product users $^{21}$. For example, while peer or social influence has been found to positively influence the use of hookahs and e-cigarettes by college students ${ }^{22-24}$, a study has also shown that social motives were negatively associated with consumption of smokeless tobacco in this population ${ }^{21}$. In addition, studies have found mixed evidence on whether young adults are using e-cigarettes more for enjoyment or for harm reductions (i.e. as a potentially less harmful alternative to cigarettes or as a cessation aid $)^{23,25}$. An investigation of motives for use, continuation, and cessation of each product will be crucial to the development of appropriate behavioral interventions aiming at prevention or cessation, as well as policies to regulate these products.

This study used qualitative methods to assess young adults' experiences with cigarettes and ATPs, specifically LCCs, smokeless tobacco, e-cigarettes and hookahs. For each product, we examined: 1) reasons for initiating use, 2) reasons for continued use, and 3) potential motivations for cessation and experiences with quitting. The theoretical framework guiding our study is the Social Cognitive Theory ${ }^{26,27}$, which emphasizes that a person acquires and maintains a behavior (e.g. tobacco use) through the dynamic influence of personal factors, behavioral, and environmental factors. Based on the theory, we hypothesize that factors such as outcome expectancies, coping responses, self-efficacy and environmental factors (e.g. interpersonal influences or ability to access and use different products) will play a role in influencing reasons for tobacco uptake and continued use, as well as potential motivations for cessation.

\section{METHODS}

\section{Participants and procedures}

The parent study, Project DECOY (Documenting Experiences with Cigarettes and Other Tobacco in Young Adults) is a two-year, six-wave longitudinal cohort study that involves 3418 racially/ethnically diverse students (18-25 years) from seven colleges and universities in Georgia. Schools are located in both rural and urban settings, and include two public universities/colleges, two private universities, two community/technical colleges, and one historically black university. Project DECOY was approved by the Emory University and ICF Institutional Review Boards, as well as those of the participating colleges 
and universities. Data collection began in Fall 2014 and consisted of self-report assessments via an online survey every four months for two years (during Fall, Spring, and Summer).

Detailed information on sampling and recruitment are described elsewhere ${ }^{28}$ and briefly summarized here. The registrar's office from each campus provided e-mail addresses for English-speaking students 1825 years. We randomly selected 3000 email addresses from each of the three largest campuses and emailed a census of students at the four smaller campuses with fewer than 3000 students. Response rates at the campuses ranged from $12.0 \%$ to $59.4 \%$. The overall response rate of $22.9 \%(\mathrm{~N}=3574 / 15607)$, albeit low, was obtained over a short time frame (24 hours at the private schools, seven days at the technical colleges) and met the sampling quota targets $^{28}$. Our intent was to enroll participants who were engaged in email and were potentially more likely to be retained in the subsequent waves of the larger, multi-wave longitudinal project. The sociodemographic characteristics of the baseline sample were largely reflective of the student bodies of the college campuses included in this study; however, the sample was disproportionately female ${ }^{28}$.

We recruited via email the users of each tobacco product (cigarettes, little cigar/cigarillos [LCCs], smokeless tobacco, electronic cigarettes [e-cigarettes], and hookahs) identified at Wave 2 of Project DECOY to participate in semi-structured interviews during Summer 2015. Eligibility criteria for this part of the study were: 1) used cigarettes, LCCs, smokeless tobacco, or e-cigarettes $\geqslant 15$ days out of the past 30 days; or 2 ) used hookah $\geqslant 10$ days out of the past 30 days (due to the lower frequency of use in this product category). Of the 99 participants recruited, $80(80.8 \%)$ consented, and $60(60.6 \%)$ actually participated in this part of the study.

\section{Measures}

Telephone-based interviews that lasted approximately 30 minutes were audio-recorded and transcribed verbatim. Participants provided verbal consent at the start of the interviews and were compensated with a $\$ 40$ Amazon gift card. The interviews were conducted by female MPH (Masters in Public Health) students trained in qualitative data collection. Sociodemographic data, derived from their baseline assessment of the longitudinal survey, and current substance use were assessed via a sort questionnaire prior to the interview. The interview guide focused on assessing reasons for initiating use of cigarettes and the respective ATPs, reasons for continued use, potential reasons for cessation, and experiences with quitting.

\section{Data analysis}

Qualitative data were analyzed using MAXQDA 12 (Berlin, Germany, http://www.maxqda.com/). Two members of the authorship team (trained MPHlevel study personnel) independently reviewed all transcripts and generated preliminary codes using deductive and inductive coding methods. A preliminary codebook for analysis was developed. Primary (major topics) and secondary (recurrent themes within primary topics) codes were established. Then, each transcript was fully and independently analyzed by two additional MPH students, and coded using the preliminary codebook. New codes that arose during this step were added to the codebook and applied to all transcripts. Codes were compared and consensus for coding was reached (kappa=93.3\%). Relevant and representative quotes were extracted for each theme. Descriptive statistics were conducted to characterize the interview sample using SPSS 23.0 .

\section{RESULTS}

\section{Participant characteristics}

Participants were on average 21.01 ( $\mathrm{SD}=2.07)$ years, $56.7 \%(n=34)$ female, and $65 \%(n=39)$ Black (Table $1)$. In terms of tobacco product use, $56.7 \%(n=34)$ reported current (past-30-day) cigarette use, $43.3 \%$ $(\mathrm{n}=26)$ LCG use, 26.7\% $(\mathrm{n}=16)$ smokeless tobacco use, $45.0 \%(n=27)$ e-cigarette use, and $41.7 \%(n=25)$ hookah use. Regarding other substance use, almost all participants $(95.0 \%, \mathrm{n}=57)$ reported current alcohol use, and half $(43.3 \%, \mathrm{n}=26)$ reported current marijuana use. Table 2 includes sample quotes for major themes that emerged from our data across the range of tobacco products.

\section{Reasons for initiation of use}

Several participants reported interpersonal influences from friends and family members as reasons for initiation of use. The majority of participants 
Table 1. Participant characteristics, $n=60$

\begin{tabular}{|c|c|}
\hline Variable & $\begin{array}{c}\text { V (SD) or } \mathrm{N} \\
(\%)\end{array}$ \\
\hline \multicolumn{2}{|l|}{ Sociodemographics } \\
\hline Age (SD) & $21.01(2.07)$ \\
\hline \multicolumn{2}{|l|}{ Sex $(\%)$} \\
\hline Female & $34(56.7)$ \\
\hline Male & $25(41.7)$ \\
\hline \multicolumn{2}{|l|}{ Race/Ethnicity (\%) } \\
\hline White & $21(35.0)$ \\
\hline Black & $39(65.0)$ \\
\hline \multicolumn{2}{|l|}{ School Type (\%) } \\
\hline Public university & $18(30.0)$ \\
\hline Private college/university & $11(18.3)$ \\
\hline $\mathrm{HBCU}$ & $9(15.0)$ \\
\hline Technical college & $22(36.7)$ \\
\hline \multicolumn{2}{|l|}{ Residence Type } \\
\hline Dorm/residence hall & $13(21.7)$ \\
\hline At home/with parents & $14(23.3)$ \\
\hline Other off-campus apartment or house & $33(55.0)$ \\
\hline \multicolumn{2}{|l|}{ Employment } \\
\hline Not employed & $18(30.0)$ \\
\hline Employed part-time & $33(55.0)$ \\
\hline Employed full-time & $9(15.0)$ \\
\hline \multicolumn{2}{|l|}{ Tobacco-Related Measures } \\
\hline \multicolumn{2}{|l|}{ Past-30-day tobacco use (\%) } \\
\hline Cigarettes & $34(56.7)$ \\
\hline LCCs & $26(43.3)$ \\
\hline Smokeless tobacco & $16(26.7)$ \\
\hline E-cigarettes & $27(45.0)$ \\
\hline Hookah & $25(41.7)$ \\
\hline \multicolumn{2}{|l|}{ Other Substance Use } \\
\hline Number of days alcohol use, past 30 days (SD) & $7.65(7.86)$ \\
\hline Any marijuana use, past 30 days (\%) & $26(43.3)$ \\
\hline
\end{tabular}

discussed initiating tobacco use because they felt pressured by their friends or wanted to feel like they 'fit in' with their social groups. Additionally, seeing or growing up with parents and siblings using tobacco (familial influence) was also mentioned as a reason for initiation of use of cigarettes and LCCs for some participants. For example, a cigarette smoker said: 'If my sister hadn't smoked whenever I was younger and she wasn't around, I probably never would have picked up the habit'. Another said: 'I learned about [little cigars and cigarillos] because my father used to... Well, he still does smoke them. I don't want to say parental influence, but I mean, I've been around it since I was a kid, so you copy what you see...'.

Apart from interpersonal influences, many participants stated reasons related to their perceptions of product characteristics. LCCs, smokeless tobacco, e-cigarettes and hookahs appealed to participants because of either the variety of flavors or the fact that these products did not taste or leave behind smells as 'strong' or 'bad' as cigarettes. For example, a participant who used cigarettes, smokeless tobacco, and hookahs said that, in regard to smokeless tobacco use, 'the flavoring is probably the most crucial part of it, because if there wasn't a flavor that I liked then I wouldn't want to use it... So the flavor is definitely essential to use and selection of smokeless tobacco'. A user of cigarettes, smokeless tobacco, and hookah stated in regard to hookahs that 'The smell and the flavor were both nice, real fruity, didn't really smell necessarily bad afterwards. The room smelled kind of good'.

\section{Table 2. Themes and sample responses regarding reasons for use initiation, continued use, and potential} cessation among young adult tobacco users

\section{Theme Sample quote}

Reasons for

initiation of use

Cigarettes

Peer influence

Everything that I tried was in a social setting. It was other people who had been doing it longer than me telling me try this, like it'll make you feel better, or this cigarette goes along really well with marijuana, or smoke and drink at the same time, it's a really fun thing. So me being sheltered from my family, being naive, I didn't really know too much about any substances or anything, so I went based on what all of my friends said. It was never like pressure. I always just gave into it pretty easy, but I would say that my friends are the reason that I did anything at all. - White female; cigarette and e-cigarette user

I would definitely say it's peer pressure, like everybody knows it is most of the time. - White female; cigarette and e-cigarette user 
Table 2. Continued

Theme Sample quote

Reasons for

initiation of use

Familial influence Well, if my sister hadn't smoked whenever I was younger and she wasn't around, I probably never would have picked up the habit, just because the whole reason I tried it is because it was there. - White female; cigarette user

Well, my parents have always smoked regular cigarettes, so it's just kind of been something that was always around. - White female; cigarette user

\section{Little cigars/cigarillos (LCCs)}

Peer influence I guess when I first started it was kind of like just to fit in with my friends. - White male; smokeless tobacco user

Well, when I started smoking Blacks I mean, it seems like more and more of my friends started smoking them also so I would say my social life did play a major role in it - Black female; cigarette and LCC user

Familial influence $\mathrm{Oh}$, yeah, I learned about them because my father used to... Well, he still does smoke them. I don't want to say parental influence, but I mean, I've been around it since I was a kid, so you copy what you see, so... Black female; LCC user

Flavors and tastes Because they have the different filters with the fragrances to them, so it cuts that tobacco smell, so I can tolerate those better than the straight tobacco. - Black female; LCC user

Costs

Well, Black and Milds are always less than a dollar, and they're so cheap. It's so cheap to get it and easy to get it, so why not just try that instead of going onto different and harder drugs? - Black female; cigarette and LCC user

Smokeless tobacco

Peer influence Just peer pressure, fitting in, stuff like that. Social... - White male; cigarette and smokeless tobacco user

Flavors and tastes As far as dip goes, the flavoring is probably the most crucial part of it, because if there wasn't a flavor that I liked then I wouldn't want to use it, because I've tried the unflavored, and I didn't like the non-flavored version. So the flavor is definitely essential to use and selection of smokeless tobacco. - White male; cigarette, smokeless tobacco, and hookah user

Ease of access I was just bored sitting in my dorm room. I was too young to be able to buy alcohol, and at that time I really didn't smoke marijuana that much or really at all, didn't really know where to find it, so I was just bored, went and got a can of dip, and just went back to my room and played video games while using the product. - White male; cigarette, smokeless tobacco, and hookah user

\section{E-cigarettes}

Peer influence

I would say that it had a major impact just because when you see a lot of people doing it, you want to do it too, and I mean, you don't want to be the odd one out, so most of the time we just give in. - White female; cigarette and e-cigarette user

Flavors and tastes E-cigarettes tasted so much better. You didn't really have that like metal-y taste in your mouth afterwards. It's like fruity. You can get something else out of it. And the taste doesn't linger. - White female; e-cigarette and hookah user

Potentially less harmful alternative

Cessation aid Because from what I had heard from everybody it was supposed to be a better alternative to smoking, and it was supposed to be healthier for you. - White female; cigarette user

I think it's mainly because it's said to be safer and more healthy. I guess it's sort of a safer alternative unlike cans of tobacco, they always have it on the cans that this isn't a safer alternative for cigarettes, so I think that's mainly what it is about is that like it's trying to get people to quit smoking cigarettes, because there's not really anything harmful about e-cigs. I think that's the whole point of them. - White male; cigarette, smokeless tobacco, and hookah user

My mom had been reading online about them, and they purchased one for me for an early Christmas present last year, and it was relatively easy to quit smoking cigarettes when I had this to switch it out with. I had tried to quit without anything, just cold turkey, and it was near impossible for me, but it was really, really easy to just switch out buying cigarettes with using the electronic cigarette, and like I said, going down on the nicotine has really helped me as well. - White female; e-cigarette user

Ease of access I used to smoke the e-cigarettes and the vape pens inside of school because you can't obviously smoke a cigarette in the school, so as fun I would smoke one. - White male; cigarette and hookah user 
Table 2. Continued

\section{Theme Sample quote}

Reasons for

initiation of use

\section{Hookahs}

Peer influence Like if my friends are already doing it then I would just go ahead and join in with them, like if they're all using it, then I'm just going to join them in it. - Black female; hookah user

Flavors and tastes Yes, I feel like flavor matters, because smoking regular products versus flavored products also adds a bit of excitement and intrigue to whatever product you're smoking, especially in the case of hookah. - Black male; hookah user

The smell and the flavor were both nice, real fruity, didn't really smell necessarily bad afterwards. The room smelled kind of good. It just smelled like the hookah smoke, so it wasn't bad. - White male; cigarette, smokeless tobacco, and hookah user

Potentially When it first came out, it was advertised as more so of a safe tobacco use, and you don't have to have it less harmful with the nicotine, and all the other negative things that are associated with cigarettes and everything, so it alternative almost was like a safe way of smoking, I guess you would say. So that was really what drew my attention to it. - Black female; hookah user

\section{Influences on continued use}

\section{Cigarettes}

Peer influence

Like whenever I'm like around people and they're like talking and smoking cigarettes, it'll make me like want to smoke like while I'm talking with them, because I feel like kind of left out. - Black male; cigarette, $L C C$, and e-cigarette user

Stress management I use them to manage stress because I am a college student. I'm a wife. I'm a homeowner. My family is very big, very old, very stressful, so yeah, there's a lot of stress that comes into my life, and those are basically my outlets. If I'm not reading a book, then I'm usually smoking marijuana or having a cigarette while I'm reading a book with a cup of coffee. - White female; cigarette user

Part of it would be that being in school you do get stressed out, when you have finals, you have a bunch of tests, you have homework due, quizzes, things like that, and so doing that you think, okay, well, I'm stressed out. I need something to do. And also I used to work at a restaurant/bar which is a really stressful environment. - White male; cigarette and hookah user

Co-use with Well, cigarettes they tend to be smoked more while you're drinking, so when we're at a bar with friends, or alcohol at a house party we tend to smoke cigarettes more. - White female; cigarette user

If there's alcohol involved, of course cigarettes are involved as well. - White female; cigarette user

Little cigars/cigarillos (LCCs)

Peer influence

Peer pressure is real. When you're in a social setting, I feel in my eyes that it's okay, because you're in a social setting. - Black female; LCC user

Stress management

Most times I will go to it if I am feeling a little stressed, or if I'm stressed, and I just want to try to relax. Black male; cigarette and LCC user

Because I am a college student, and my major is very demanding, so around certain exams that I have to take, that's when my stress level is really high, and then personal things that are going on in my life at the time, that'll trigger off my stress and cause me to want to smoke, so I would use them then. That's about it, just personal things that cause my stress. That's when I'Il pick up a cigar and smoke that. - Black female; LCC user

Instrument for About 15 times [a month], like I use them to roll the marijuana with, just take the tobacco out and then marijuana use put the marijuana in it and just roll it back up. - Black male; cigarette and LCC user

Smokeless tobacco

Stress management

Addictiveness
I liked the relaxing qualities of it. I have minor anxiety issues, and it took the edge off and helped me calm down. That's one of the reasons why I use some of the smokeless tobacco stuff. - White male; smokeless tobacco user

I think that with smokeless tobacco it increased a lot whenever I first started, and now it's kind of remained the same for a while now. I think it was because at first I didn't really like it. I just kind of did it because my friends were doing it, and then after a while I became addicted to the nicotine, so then it was more of like I had cravings for it all the time. - White male; smokeless tobacco user 
Table 2. Continued

Theme Sample quote

Reasons for

initiation of use

The cost really doesn't affect it. The cost has definitely gone up since I first started, but I'll buy it because I crave it and I'm addicted to it. - White male; smokeless tobacco user

Ease of access I guess in a situation where you can't smoke like in a classroom or in like an environment where smoking is not allowed. - White male; cigarette and smokeless tobacco user

E-cigarettes

Flavors and tastes When I first started it was a friend that I would just try it when she had it out, and then we would like to try just the different flavors of it, so now I know which flavors that I like, because now that I have my own, and I like the flavors. - White female; e-cigarette user

Potentially less harmful alternative

Cessation aid Well, the advertisement and stuff where it talks about how much better it was like for your health and stuff. And a lot of people liked it. - White female; e-cigarette user

Stress management

Ease of access

The whole idea behind it was to try and quit completely. So when I started at 25 , I slowly worked my way down to the lower nicotine levels, and l've been stuck at six. - White male; e-cigarette user.

I carry a small one around with me just in case, because it occasionally gets really bad, and I do get panic attacks, and they're just a helpful thing to help me calm down afterwards. - White male; smokeless tobacco and e-cigarette user

Well, they just implemented a no smoking policy that's going to take effect here in August, and so a lot of my friends have bought electronic cigarettes to use instead, because you can smoke those in your car or in your dorm, and it doesn't have a smell. - White female; cigarette and e-cigarette user

\section{Hookahs}

Peer influence

It's something I have to do with a group of people. I would feel really weird doing it by myself. - White female; e-cigarette and hookah user

Hookah is a really big social kind of use, just sitting around smoking with your friends and talking. - White male; cigarette, smokeless tobacco, and hookah user

Flavors and tastes I think it's kind of cool when hookah has different flavors that you can actually taste, but everything else, it doesn't really matter to me. - White male; cigarette and hookah user

Co-use with When I'm out with friends and we're drinking and just kind of relaxing, I guess you would say with alcohol alcohol in a nice night out with friends - Black female; hookah user

Experiences with cessation

Cigarettes

Motivations to quit

Pressure from interpersonal network

Family responsibilities

Concern about current and future health

Physical appearance
With cigarettes, I really wanted to stop that because like I said before, it generally made me feel terrible. I kind of felt like I had bronchitis all the time. White male; e-cigarette user

I had my parents pushing me to quit as well. Neither of them smokes cigarettes or used any kind of tobacco growing up, when I was growing up, and so they really wanted me to quit for my health and everyone around me. Their health as well. - White female; e-cigarette user

I would love to stop after I graduate. If I end up not quitting after I graduate, then when I conceive my first child, I would definitely quit then. That's it, done. - White female; cigarette user

Because I have a son, and he does -- he did have heart problems. I feel as though if anything were to happen to me, I don't know who would take up for him or who would care for him, so I mean, I can't do anything to hurt my body anymore, because I have other priorities to look at. I have a kid to take care of. - Black female; cigarette user

Number one being my health. Really don't want to get cancer or anything like that. - White female; cigarette user

My hygiene, because smoking cigarettes stinks and I know it does, and I don't want to stink every time I walk past somebody just because I smell like an ash tray. My appearance, as well, because smoke sticks to your skin, it makes you wrinkly, it makes you age quicker, it ruins your teeth. It's really not worth it. White female; cigarette user 
Table 2. Continued

\section{Theme Sample quote}

Reasons for initiation of use

Costs

My main reasoning is of course financial reasons. I would spend who knows how much money per week, especially per week on just tobacco, so it was definitely financial reasons as well as just I wanted to test myself to see if I even could quit, and I did, and was able to. - White male; cigarette, smokeless tobacco and hookah user

\section{Cessation strategies and attempts}

Avoidance of other tobacco users

Reduction of nicotine intake

Put myself in fewer situations where people around me will be using them. - Black male; cigarette, LCC, e-cigarette, and hookah user

Definitely using the e-cigarette more than normal cigarettes to get the nicotine, because it's a lower dosage of nicotine, and working my way down. - White female; cigarette and e-cigarette user

I used Nicoderm CO patches initially to break the habit first. With the patches you can control the nicotine, too. So, I don't know - either the patches or the e-cigs. They may help versus cold turkeying. - White female; cigarette user

Little cigars/cigarillos (LCCs)

\section{Motivations to quit}

Concern about I quickly learned that one Black and Mild equals about 20 cigarettes so I put down Black and Milds and got current and the cigarettes. - Black female; cigarette user

future health

\section{Cessation strategies and attempts}

Avoidance of other tobacco users

Focus redirection
I think it will be easier for a lot of other people to quit if they would stop hanging around people that are doing the same thing that they're trying to stay away from... [My friends] were still doing it, but I just kind of didn't. - Black female; LCC user

Well, as long as I occupy my time with something productive to ease my mind off of running to a clove or a Black or whatever it is. - Black female; cigarette user

\section{Smokeless tobacco}

\section{Motivations to quit}

Pressure from interpersonal network

Concern about current and future health
I've stopped for the purpose of satisfying someone else, a request from you know, like a girlfriend let's say. Not a personal request. So I've quit for someone else, you know, as long as I needed to, and then when I didn't need to fulfill that anymore, then I began dipping again, because I didn't personally want to quit. I was, you know, quitting for the sake of someone else, and after I didn't need to do that anymore, then I began to dip again. - White male; cigarette, smokeless tobacco, and hookah user

There was no direct reasoning except for I knew that it was not good for me. I knew that using it was detrimental to my health so I stopped using it. - White male; smokeless tobacco user

\section{Cessation strategies and attempts}

Focus redirection As I was quitting, whenever I would get a craving, I would always substitute that with either reading or exercising. If I craved I would just open up a book for a couple of minutes or go on a run, stuff like that. White male; cigarette, smokeless tobacco, and hookah user

\section{E-cigarettes}

Motivations to quit

Family responsibilities

I have the family on my mind right now. I want a family one day and I want to be around for my family one day, and I wouldn't necessarily want my kids to see me smoke or to be around anything like that. White female; e-cigarette and hookah user

Costs Well, even though it's less expensive than smoking cigarettes, it's still an expense, and it's money that I could use in other places, and it's really an unnecessary expense. It's mostly something that I do now just out of boredom, and so I guess that would be the main reason for quitting. - White male; e-cigarette user 
Table 2. Continued

\begin{tabular}{|c|c|}
\hline $\begin{array}{l}\text { Theme } \\
\text { Reasons for } \\
\text { initiation of use }\end{array}$ & Sample quote \\
\hline $\begin{array}{l}\text { Reduction of } \\
\text { nicotine intake }\end{array}$ & $\begin{array}{l}\text { I've already reduced my nicotine content three times. I started at } 18 \text { worked way down to } 16,14-\text { Well } \\
\text { I guess this is the fourth time, I'm on } 12 \text {. I've brought my nicotine content down four times, and I'm } \\
\text { planning on going down again in the next couple of months and then continuing on until I'm down to } \\
\text { zero, and then I'm going to just try to quit the habit then. - White female; e-cigarette user }\end{array}$ \\
\hline \multicolumn{2}{|l|}{ Hookahs } \\
\hline \multicolumn{2}{|c|}{ Motivations to quit } \\
\hline $\begin{array}{l}\text { Family } \\
\text { responsibilities }\end{array}$ & $\begin{array}{l}\text { Once I'm married and I have children and stuff like that, I doubt I would just say oh, let me go hit up the } \\
\text { hookah lounge tonight while I have my kids at home. So it probably wouldn't be as recreational, but say } \\
\text { for instance my husband and I are away on vacation or something and we decide to stop at a hookah bar, } \\
\text { something like that, I don't see anything wrong with that, but I don't think it would be as prevalent in my } \\
\text { life if I was married with children. - Black female; hookah user }\end{array}$ \\
\hline $\begin{array}{l}\text { Concern about } \\
\text { current and } \\
\text { future health }\end{array}$ & $\begin{array}{l}\text { Just the health risks, and I run and stuff a lot, and I could feel it affecting. - White male; cigarette, } \\
\text { smokeless tobacco, and hookah user }\end{array}$ \\
\hline \multicolumn{2}{|c|}{ Cessation strategies and attempts } \\
\hline $\begin{array}{l}\text { Avoid other } \\
\text { tobacco users }\end{array}$ & Less social interaction with people who use these products. - Black male; hookah user \\
\hline
\end{tabular}

Several participants also perceived e-cigarettes and hookahs as 'safer' alternatives to cigarettes. E-cigarettes, in particular, were also used as a cessation aid, and participants mentioned initiating use of e-cigarettes to 'transition away' from cigarettes and gradually reduce the amount of nicotine intake. A user of e-cigarettes said: 'I had tried to quit [cigarettes] without anything, just cold turkey, and it was near impossible for me, but it was really, really easy to just switch out buying cigarettes with using the electronic cigarette, and like I said, going down on the nicotine has really helped me as well'.

In addition to reasons for initiation of use related to interpersonal influences, perception of product characteristics, and lower perceived health risks, reasons related to ease of product access and low levels of regulations were also mentioned by a few participants. Smokeless tobacco was reported to be more easily located and purchased compared to other substances, such as marijuana or alcohol among college students. Some users of e-cigarettes stated that they could use e-cigarettes in places where cigarettes were not allowed, such as inside schools. For LCCs, low costs were also a reason for product uptake.

\section{Influences on continued use}

Several themes already acknowledged as reasons for initiation of use were also identified by participants as influences on their continuation of product use. The majority of participants mentioned peer influence (cigarettes, LCGs and hookahs) and flavors and tastes (e-cigarettes and hookahs). In addition, many discussed reasons such as potentially less harmful alternative to cigarettes (e-cigarettes), cessation aid (e-cigarettes), and ease of access (smokeless tobacco and e-cigarettes).

Moreover, stress management was mentioned by the majority of participants as a reason why they continued to use cigarettes, LCCs, smokeless tobacco, and e-cigarettes. Several participants reported that using tobacco products helped with stress related to schoolwork, stress related to job and family responsibilities, and anxiety issues. A few users of smokeless tobacco also brought up the aspect of addictiveness. A participant who used smokeless tobacco stated that 'After a while I became addicted to the nicotine, so then it was more of like I had cravings for it all the time'.

Use with other substances, such as alcohol or marijuana, was also identified as an influence on continuation of use for some participants, especially for cigarettes, LCCs, and hookahs. For instance, a cigarette user said: 'Cigarettes they tend to be smoked more while you're drinking, so when we're 
at a bar with friends, or at a house party we tend to smoke cigarettes there'. A user of cigarettes and LCGs described: 'About 15 times [a month], like I use [LCCs] to roll the marijuana with, just take the tobacco out and then put the marijuana in it and just roll it back up'.

\section{Experiences with cessation}

Participants reported several motivations to quit using tobacco products as well as cessation strategies. In terms of motivations to quit, a theme for most products (all except for LCCs) was interpersonal influences, such as pressure from others around them or family responsibilities. Women, in particular, often cited pregnancy or responsibilities associated with raising children as reasons for cessation. For example, a user of cigarettes said that 'When I conceive my first child, I would definitely quit [smoking cigarettes] then. That's it, done'. Another participant who used cigarettes said: 'I can't do anything to hurt my body anymore, because I have other priorities to look at. I have a kid to take care of'. Apart from interpersonal influences, several participants also discussed concerns about current and future health associated with using cigarettes, LCCs, smokeless tobacco, and hookahs. A user of e-cigarettes shared that he wanted to quit using cigarettes because '[cigarettes] generally made me feel terrible. I kind of felt like I had bronchitis all the time'. Additionally, a user of smokeless tobacco stated: 'There was no direct reasoning [for quitting] except for I knew that it was not good for me. I knew that using it was detrimental to my health so I stopped using it'.

Moreover, several users of cigarettes cited physical appearance as a motivation for cessation. A user of cigarettes said that 'I don't want to stink every time I walk past somebody just because I smell like an ash tray'. For cigarettes and e-cigarettes, costs and perceived high spending on these products were also a reason why several participants attempted to quit.

In terms of past cessation attempts as well as future strategies for cigarettes, LCCs, and hookahs, several participants said that they would avoid other users or social situations that would make them want to use these products. For example, a user of cigarettes, LCC, e-cigarettes, and hookahs described her strategy to stop smoking cigarettes as '[to] put myself in fewer situations where people around me will be using them'. Redirecting focus onto other activities was another common cessation strategy for users of LCCs and smokeless tobacco. A user of cigarettes, smokeless tobacco and hookahs stated: 'Whenever I would get a craving [for smokeless tobacco], I would always substitute that with either reading or exercising'.

Additionally, the majority of users of cigarettes and e-cigarettes discussed cessation strategies that included a gradual reduction of the amount of nicotine intake. Many cigarette smokers described the use of e-cigarettes and nicotine replacement therapy (NRT) for lowering their nicotine dosage. The majority of users of e-cigarettes also talked about how they decreased their nicotine intake. A participant who used e-cigarettes said: 'I've brought my nicotine content down four times, and I'm planning on going down again in the next couple of months and then continuing on until I'm down to zero, and then I'm going to just try to quit the habit then'.

\section{DISCUSSION}

Our qualitative study of 60 users of cigarettes, LCCs, smokeless tobacco, e-cigarettes, and hookahs in Georgia yields several important findings with implications for research and practice. Consistent with the Social Cognitive Theory, we found that factors from the three domains of determinants (cognitive, behavioral, and environmental) drive not only use but also attempted cessation of different tobacco products. For example, perceptions regarding safety of products and of one's own health (knowledge and outcome expectancies) motivated participants to use certain products (e.g. e-cigarettes) and to attempt quitting others (e.g. cigarettes or smokeless tobacco). Interpersonal influences from family and friends (environmental factors) were the reasons for initiation and continued use across cigarettes and all ATPs and also played an important role as a motivation for cessation for most products. Additionally, for all products assessed except for cigarettes, easy access and variety in flavors and tastes (environmental factors) influenced participants' uptake and continued use of these emerging products. Below we highlight how our results can inform future development of prevention and cessation interventions targeting young adults 
using cigarettes and ATPs, as well as policy and regulations of these products.

Our results suggest that interpersonal-related factors play an important role in the different stages of tobacco use initiation, continuation, and cessation among young adults. Evidence in the literature supports these findings. Studies have established that parental smoking is associated with a higher risk of smoking uptake in adolescent offspring ${ }^{29}$, and that parental and peer smoking are associated with daily smoking and lifetime nicotine dependence among young adults in the United States ${ }^{30}$. Recent research on ATPs has also demonstrated that peer influence is associated with experimentation with, and/or continued use of, smokeless tobacco ${ }^{31-33}$, e-cigarettes ${ }^{23,34}$, and hookahs ${ }^{24}$ among adolescents and young adults. Thus, public health professionals should consider these influences and take into account interpersonal relationship dynamics ${ }^{35}$ in designing and implementing interventions for various tobacco products. For example, interventions can focus on building resistance to negative influences and peer pressure, improving decision-making skills and assertiveness ${ }^{36}$, and employing 'quit buddies' or peers who are former tobacco users ${ }^{37}$ to provide support for those trying to quit. In addition, our findings also show that concerns with family responsibilities, such as pregnancy or childcare duties, can be a powerful motivation for cessation for users of different tobacco products. Further research should explore how to incorporate such motivation into risk communication strategies and counseling for current users.

In addition, health concerns emerged as a major reason for cessation of cigarettes, LCCs, smokeless tobacco, and hookahs. The extant literature has also established that health concerns are the primary motivation for quit attempts by cigarette users ${ }^{38}$. Our study extends the relevance of this issue to young adult users of other tobacco products, and future studies should continue to investigate how experiences of current health problems or perceived risks of health problems in the future play a role in cessation attempts and success.

Additionally, participants discussed use of tobacco products and other substances, such as alcohol or marijuana, as an influence on continued use. These co-use patterns of college students and young adults in the United States have also been noted in previous studies $^{39-41}$. Interventions thus should jointly target these behaviors, and additional research is needed to identify effective models for co-occurrence prevention and treatment ${ }^{41}$. Furthermore, while the qualitative nature of our study prevents us from providing estimates of prevalence data, we do note that a high proportion of participants were polytobacco users, i.e. using more than one product. The trend of increasing poly-tobacco use in young adults has also been noted in the literature ${ }^{42}$, and these findings point to a need for tobacco treatment strategies that target both single product tobacco users and poly-tobacco users ${ }^{43}$.

Finally, the study also suggests directions for future policy and regulations regarding cigarettes and ATPs. First, the Tobacco 21 laws, which seek to raise the minimum legal age of cigarette purchase to 21 years, can potentially have great effects on reducing initiation rates, not only among adolescents but also among young adults aged $18-20$ years $^{44}$. Evidence shows that Tobacco 21 laws are ready to go to scale, as they are effective, garner public support, and have minimal effect on retailers ${ }^{45,46}$. In addition, while the Family Smoking Prevention and Tobacco Control Act of 2009 put into place a ban on flavored cigarettes ${ }^{47}$, currently few federal regulations exist for flavors of non-cigarette products. In our study, flavors and tastes were brought up as a reason for initiation of all products except for cigarettes, and were also an influence on continued use of e-cigarettes and hookahs. Evidence also shows that young adults who are most likely to use flavored products may also be those most at risk of developing established use patterns that persist throughout their life time ${ }^{48}$. Therefore, tobacco control policymakers should pay attention to these findings in deciding measures to control sale of flavored non-cigarette products, which can help curtail uptake and continuation of use in young adults. Additionally, participants also discussed low regulations on environmental access and low costs of ATPs. Many products, for example smokeless tobacco, are indeed currently marketed for use where cigarettes are not allowed ${ }^{49}$. These results suggest a need for policy that limits accessibility to different tobacco products. For example, policy can further restrict indoor use of products and increase tax or prices on these products. These actions can help reduce prevalence of use among young adults. 


\section{Limitations}

The following limitations should be considered when interpreting results from this study. First, these are qualitative findings from a sample of 60 tobacco users in the state of Georgia, and are not intended to be generalizable. Rather, our findings serve to inform future generalizable studies on a larger scale ${ }^{50}$. Second, our findings are based on self-reported data from a relatively small sample of users and do not include biochemical verification of tobacco use or follow-back verification of the number of days of use in the past month. Third, these findings are limited to a specific adult age range (18-25 years). Future studies could seek to identify and compare themes among older adult tobacco users.

\section{CONCLUSIONS}

The increasing popularity of ATPs in the United States is concerning. Young adult college students are one of the groups with the highest use prevalence of these products. This study provides data on reasons for initiation, continuation, and potential cessation of use of different tobacco products among this population. Future research should take into account interpersonal influences on these different stages of use and cessation, and explore how to incorporate health concerns and perceived health risks into counseling for cessation. In addition, we highlight a need for regulatory action that limits diversification and accessibility of different tobacco products.

\section{REFERENCES}

1. Popova L, Ling PM. Alternative tobacco product use and smoking cessation: a national study. Am J Public Health. 2013;103(5):923-30. doi:10.2105/ajph.2012.301070

2. Berg CJ, Stratton E, Schauer GL, Lewis M, Wang Y, Windle $\mathrm{M}$, et al. Perceived harm, addictiveness, and social acceptability of tobacco products and marijuana among young adults: marijuana, hookah, and electronic cigarettes win. Subst Use Misuse. 2015;50(1):79-89. doi: 10.3109/10826084.2014.958857

3. Kozlowski LT, Dollar KM, Giovino GA. Cigar/cigarillo surveillance: limitations of the U.S. Department of Agriculture system. Am J Prev Med. 2008;34(5):4246. doi:10.1016/j.amepre.2007.12.025

4. McMillen R, Maduka J, Winickoff J. Use of emerging tobacco products in the United States. J Environ Public Health. 2012;2012:989474. doi:10.1155/2012/989474

5. Lee YO, Hebert CJ, Nonnemaker JM, Kim AE. Multiple tobacco product use among adults in the United States: cigarettes, cigars, electronic cigarettes, hookah, smokeless tobacco, and snus. Prev Med. 2014;62:14-9. doi:10.1016/j.ypmed.2014.01.014

6. Regan AK, Dube SR, Arrazola R. Smokeless and flavored tobacco products in the U.S.: 2009 Styles survey results. Am J Prev Med. 2012;42(1):29-36.

doi:10.1016/j.amepre.2011.08.019

7. Wray RJ, Jupka K, Berman S, Zellin S, Vijaykumar S. Young adults' perceptions about established and emerging tobacco products: results from eight focus groups. Nicotine Tob Res. 2012;14(2):184-90. doi:10.1093/ntr/ntr168

8. Duke JC, Lee YO, Kim AE, Watson KA, Arnold KY, Nonnemaker JM, et al. Exposure to electronic cigarette television advertisements among youth and young adults. Pediatrics. 2014;134(1):e29-36. doi:10.1542/peds.2014-0269

9. Richardson A, Williams V, Rath J, Villanti AC, Vallone D. The next generation of users: prevalence and longitudinal patterns of tobacco use among US young adults. Am J Public Health. 2014;104(8):1429-36.

doi:10.2105/ajph.2013.301802

10.L M Dutra; R A Grana; L Lempert JJKCSAGBLHFPMLLPMW,. FDA Should Restrict E-cigarette Marketing to Protect Youth as Part of the Currently Proposed Regulation. 2014. Contract No.: Docket No. FDA2014-N-0189.

11. Roberts ME, Lu B, Browning CR, Ferketich AK. Tracking Young Adults' Attitudes Toward Tobacco Marketing Using Ecological Momentary Assessment (EMA). Subst Use Misuse. 2017;52(9):1219-24. doi:10.1080/10826084.2017.1302958

12.Berg CJ, Romero DR, Pulvers K. Perceived harm of tobacco products and individual schemas of a smoker in relation to change in tobacco product use over one year among young adults. Subst Use Misuse. 2015;50(1):908. doi:10.3109/10826084.2014.958858

13. Evans-Polce R, Lanza S, Maggs J. Heterogeneity of alcohol, tobacco, and other substance use behaviors in U.S. college students: A latent class analysis. Addict Behav. 2016;53:80-5. doi:10.1016/j.addbeh.2015.10.010

14. Enofe N, Berg CJ, Nehl EJ. Alternative tobacco use among college students: who is at highest risk? Am J Health Behav. 2014;38(2):180-9. doi:10.5993/ajhb.38.2.3

15. Noland M, Ickes MJ, Rayens MK, Butler K, Wiggins AT, Hahn EJ. Social influences on use of cigarettes, e-cigarettes, and hookah by college students. J Am Coll Health. 2016;64(4):319-28. doi:10.1080/07448481.2016.1138478

16. Loukas A, Chow S, Pasch KE, Li X, Hinds Iii JT, Marti CN, et al. College Students' Polytobacco Use, Cigarette Cessation, and Dependence. Am J Health Behav. 2016;40(4):514-22. doi:10.5993/ajhb.40.4.13

17. Cooper M, Loukas A, Harrell MB, Perry CL. College students' perceptions of risk and addictiveness of 
e-cigarettes and cigarettes. J Am Coll Health. 2016:19. doi:10.1080/07448481.2016.1254638

18. VanDevanter N, Zhou S, Katigbak C, Naegle M, Sherman S, Weitzman M. Knowledge, Beliefs, Behaviors, and Social Norms Related to Use of Alternative Tobacco Products Among Undergraduate and Graduate Nursing Students in an Urban U.S. University Setting. J Nurs Scholarsh. 2016;48(2):147-53. doi: 10.1111/jnu.12192

19. Latimer LA, Batanova M, Loukas A. Prevalence and harm perceptions of various tobacco products among college students. Nicotine Tob Res. 2014;16(5):519-26. doi: $10.1093 / \mathrm{ntr} / \mathrm{ntt} 174$

20. Rath JM, Villanti AC, Abrams DB, Vallone DM. Patterns of tobacco use and dual use in US young adults: the missing link between youth prevention and adult cessation. J Environ Public Health. 2012:1-9. doi:10.1155/2012/679134

21. Wong EC, Haardorfer R, Windle M, Berg CJ. Distinct Motives for Use among Polytobacco Versus Cigarette Only Users and among Single Tobacco Product Users. Nicotine Tob Res. 2016. doi:10.1093/ntr/ntw284

22. Braun RE, Glassman T, Wohlwend J, Whewell A, Reindl DM. Hookah use among college students from a Midwest University. J Community Health. 2012;37(2):294-8. doi:10.1007/s10900-011-9444-9

23. Kong G, Morean ME, Cavallo DA, Camenga DR, Krishnan-Sarin S. Reasons for Electronic Cigarette Experimentation and Discontinuation Among Adolescents and Young Adults. Nicotine Tob Res. 2015;17(7):84754. doi:10.1093/ntr/ntu257

24. Castaneda G, Barnett TE, Soule EK, Young ME. Hookah smoking behavior initiation in the context of Millennials. Public Health. 2016;137:124-30. doi:10.1016/j.puhe.2016.02.013

25. Saddleson ML, Kozlowski LT, Giovino GA, Goniewicz ML, Mahoney MC, Homish GG, et al. Enjoyment and other reasons for electronic cigarette use: Results from college students in New York. Addict Behav. 2016;54:339. doi:10.1016/j.addbeh.2015.11.012

26. Bandura A. Social foundations of thought and action: A social cognitive theory. Englewood Cliffs, NJ: Prentice Hall; 1986.

27. Bandura A. Health promotion from the perspective of social cognitive theory. Psychology and Health. 1998;13:623-49. doi:10.1080/08870449808407422

28. Berg CJ, Haardörfer R, Lewis M, Fakhouri T, Getachew B, Lloyd S, et al. DECOY: Documenting Experiences with Cigarettes and Other Tobacco in Young Adults. American Journal of Health Behavior. 2016;40(3):31021. doi:10.5993/ajhb.40.3.3

29. Gilman SE, Rende R, Boergers J, Abrams DB, Buka SL, Clark MA, et al. Parental smoking and adolescent smoking initiation: an intergenerational perspective on tobacco control. Pediatrics. 2009;123(2):e274-81. doi:10.1542/peds.2008-2251
30. Hu MC, Davies M, Kandel DB. Epidemiology and correlates of daily smoking and nicotine dependence among young adults in the United States. Am J Public Health. 2006;96(2):299-308.

doi:10.2105/ajph.2004.057232

31. Maxwell KA. Friends: The Role of Peer Influence Across Adolescent Risk Behaviors. Journal of Youth and Adolescence. 2002;31(4):267-77.

32. Morrell HE, Cohen LM, Bacchi D, West J. Predictors of smoking and smokeless tobacco use in college students: a preliminary study using web-based survey methodology. J Am Coll Health. 2005;54(2):108-15. doi:10.3200/jach.54.2.108-115

33. Cavazos-Rehg PAK, Melissa J.; Sowles, Shaina J.; Spitznagel, Edward L.; Grucza, Richard; Chaloupka, Frank J.; Bierut, Laura J. Multiple Levels of Influence That Impact Youth Tobacco Use. Tobacco Regulatory Science. 2016;2(2):106-22. doi:10.18001/trs.2.2.2

34.Krishnan-Sarin S, Morean ME, Camenga DR, Cavallo DA, Kong G. E-cigarette Use Among High School and Middle School Adolescents in Connecticut. Nicotine Tob Res. 2015;17(7):810-8. doi:10.1093/ntr/ntu243

35. Kobus K. Peers and adolescent smoking. Addiction. 2003;98(S1):37-55. doi: 10.1046/j.1360-0443.98.s1.4.x

36. Paula M Lantza PDJ, Kenneth E Warnera, Jeffrey Wassermanb, Harold A Pollacka, Julie Bersona, Alexis Ahlstroma. Investing in youth tobacco control: a review of smoking prevention and control strategies. Tobacco Control. 2000;9(1):47-63. doi:10.1136/tc.9.1.47

37.Abroms LC, Ahuja M, Kodl Y, Thaweethai L, Sims J, Winickoff JP, et al. Text2Quit: results from a pilot test of a personalized, interactive mobile health smoking cessation program. J Health Commun. 2012;17 Suppl 1:44-53. doi:10.1080/10810730.2011.649159

38. McCaul KD, Hockemeyer JR, Johnson RJ, Zetocha K, Quinlan K, Glasgow RE. Motivation to quit using cigarettes: a review. Addict Behav. 2006;31(1):42-56. doi:10.1016/j.addbeh.2005.04.004

39. Heinz AJ, Giedgowd GE, Crane NA, Veilleux JC, Conrad M, Braun AR, et al. A comprehensive examination of hookah smoking in college students: use patterns and contexts, social norms and attitudes, harm perception, psychological correlates and co-occurring substance use. Addict Behav. 2013;38(11):2751-60.

doi: 10.1016/j.addbeh.2013.07.009

40. Ramo DE, Liu H, Prochaska JJ. Tobacco and marijuana use among adolescents and young adults: a systematic review of their co-use. Clin Psychol Rev. 2012;32(2):10521. doi: 10.1016/j.cpr.2011.12.002

41. Weitzman ER, Chen YY. The co-occurrence of smoking and drinking among young adults in college: national survey results from the United States. Drug Alcohol Depend. 2005;80(3):377-86.

doi:10.1016/j.drugalcdep.2005.05.008

42. Fix BV, O’Connor RJ, Vogl L, Smith D, Bansal-Travers M, 
Conway KP, et al. Patterns and correlates of polytobacco use in the United States over a decade: NSDUH 20022011. Addict Behav. 2014;39(4):768-81.

doi:10.1016/j.addbeh.2013.12.015

43. Butler KM, Ickes MJ, Rayens MK, Wiggins AT, Hahn EJ. Polytobacco Use Among College Students. Nicotine Tob Res. 2016;18(2):163-9. doi:10.1093/ntr/ntv056

44. Bonnie RJ, Stratton K, Kwan LY, Committee on the Public Health Implications of Raising the Minimum Age for Purchasing Tobacco Products, Institute of Medicine (U.S.). Board on Population Health and Public Health Practice. Public health implications of raising the minimum age of legal access to tobacco products. Washington, D.C.: The National Academies Press; 2015. xix, 378 pages $p$.

45. Morain SR, Winickoff JP, Mello MM. Have Tobacco 21 Laws Come of Age? N Engl J Med. 2016;374(17):16014. doi:10.1056/nejmp1603294

46. Winickoff JP, Gottlieb M, Mello MM. Tobacco 21--an idea whose time has come. N Engl J Med. 2014;370(4):2957. doi:10.1056/nejmp1314626

47. Administration USFaD. Tobacco Control Act 2016. ht t p : / / w w w.fda.gov/TobaccoProducts / GuidanceComplianceRegulatoryInformation/ ucm246129.htm. 11/07/2016. (accessed 1 October 2017).

48. Villanti AC, Richardson A, Vallone DM, Rath JM. Flavored tobacco product use among U.S. young adults. Am J Prev Med. 2013;44(4):388-91.

doi:10.1016/j.amepre.2012.11.031

49. Gartner CE, Hall WD, Chapman S, Freeman B. Should the health community promote smokeless tobacco (snus) as a harm reduction measure? PLoS Med. 2007;4(7):e185. doi:10.1371/journal.pmed.0040185

50. Hennink MM, Hutter I, Bailey A. Qualitative research methods. London: Sage; 2011.

ACKNOWLEDGEMENTS

We would like to thank our Campus Advisory Board members across the State of Georgia in developing and assisting in administering this survey. We also would like to thank ICF Macro for their scientific input and technical support in conducting this research.

\section{CONFICTS OF INTEREST}

Authors have completed and submitted the ICMJE Form for Disclosure of Potential Conflicts of Interest and none was reported.

\section{FUNDING}

This research was supported by the National Cancer Institute (1R01CA179422-01; PI: Berg). The funders had no role in the study design, collection, analysis or interpretation of the data, the writing of the manuscript or the decision to submit it for publication.

PROVENANCE AND PEER REVIEW

Not commissioned: externally peer reviewed 